\title{
CONTROLE ANTIDOPING NO BRASIL: MONITORAMENTO E PRÁTICA DE DOPAGEM
}

\author{
Leonardo de Assunção \\ Universidade Castelo Branco, Rio de Janeiro, Rio de Janeiro, Brasil \\ José Henrique dos Santos \\ Universidade Federal Rural do Rio de Janeiro, Seropédica, Rio de Janeiro, Brasil
}

\begin{abstract}
Resumo
O uso de substâncias ou métodos proibidos visando melhorar o desempenho vem se tornando mais frequente no meio esportivo. Sendo assim, o objetivo desta pesquisa é caracterizar os resultados de exames antidoping realizados no Brasil no ano de 2008 em diferentes esportes. Os dados foram coletados junto ao Laboratório de Controle de Dopagem da UFRJ e Comitê Olímpico Brasileiro, ambos credenciados pelo Comitê Olímpico Internacional e pela WADA. Naquele ano foram realizados 4.621 exames, sendo 4.587 em competição e 34 fora de competição. O futebol foi a modalidade com maior índice de positividade em ambos os tipos de exames. Os avanços científicos possibilitam métodos de controle cada vez mais sofisticados na identificação do uso de drogas no esporte.
\end{abstract}

Palavras-chave: Doping. Esporte. Jogo Limpo. Controle de drogas. Desempenho Atlético.

\section{Introdução}

$\mathrm{E}$ m 1967, o Comitê Olímpico Internacional (COI) instituiu uma comissão médica para levar a efeito o controle de dopagem, pela primeira vez, nos Jogos de Inverno de Grenoble, na França, em 1968. O status tecnológico, naquela época, permitia apenas a identificação de alguns estimulantes e narcóticos. Somente em 1976, nas Olimpíadas de Montreal, foi realizada a primeira testagem para anabolizantes (AQUINO NETO, 2001).

No ano de 2003, vários representantes de diferentes nacionalidades, incluindo o Brasil, se reuniram e assinaram a declaração de Copenhague sobre doping no esporte, criando o Código Mundial Antidoping, que tem o objetivo de preservar o espírito esportivo (CASTRO; NÓBREGA; DE ROSE, 2004). 
De Rose, Aquino Neto e Nicolich (2009, p. 10) afirmam que "o desejo do ser humano de se superar continuamente, tentando ser mais forte e mais potente, sem respeitar limites, pode ser evidenciado em todas as etapas da história da humanidade". Estas manifestações magnificam a importância de se discutir a questão do doping na sociedade contemporânea. Segundo Vieira (2006, p. 5), “o doping é definido como a utilização de uma substância estranha ao organismo com a finalidade de aumentar, artificial e deslealmente, o rendimento durante a participação em uma competição". Argüelles e Zamora (2007) afirmam que o doping se caracteriza pela presença de substâncias artificiais (drogas ou medicamentos que melhoram o desempenho dos atletas, metabolitos e marcadores) ou pela administração de uma substância ou métodos proibidos em uma amostra de sangue ou urina. $\mathrm{O}$ Comitê Olímpico Internacional e a Agência Mundial Antidoping (AMA) consideram o doping como o uso de substâncias proibidas ou métodos potencialmente perigosos para a saúde dos atletas, capazes de aumentar artificialmente sua performance.

O corpo produz substâncias para sua manutenção de forma natural. Quando a concentração dessas substâncias se desvia dos valores normalmente encontrados em humanos, detecta-se a substância proibida. De Rose, Aquino Neto,,Moreu e Castro (2004) descreveram os grupos farmacológicos proibidos mais utilizados, a saber: os estimulantes, agentes anabólicos, diuréticos e hormônios peptídicos, geralmente associados à melhoria do rendimento atlético e esportivo. Rivier (2000) comenta que existem mais de 1000 substâncias químicas que, em teoria, poderiam, direta ou indiretamente, ser utilizadas por atletas, visando o aperfeiçoamento do desempenho.

Os estimulantes são substâncias que apresentam um efeito direto sobre o sistema nervoso central, aumentando a estimulação do sistema cardíaco e do metabolismo. São usados para conseguir os efeitos da adrenalina, quais sejam o aumento da excitação e da capacidade de tolerância a dor. Por outro lado, provocam efeitos secundários potencialmente prejudiciais ao organismo, tais como a falta de apetite, hipertensão arterial, palpitações e arritmia cardíaca, alucinações e diminuição da sensação de fadiga.

Os agentes anabólicos são definidos por Robergs e Scott (2002), como uma família de hormônios esteróides similares aos hormônios naturais que aumentam a síntese protéica e a hipertrofia muscular, assim como o desenvolvimento dos caracteres sexuais secundários. De 
acordo com Silva, Danielski e Czepielewski (2002) são utilizados, por um lado, para aumentar o metabolismo basal, o número de hemácias e a capacidade respiratória; e, por outro, para reduzir a taxa de gordura corporal e proporcionar ganho de força, potência e maior tolerância ao exercício físico. Seus efeitos secundários ao organismo seriam o aumento da agressividade, aumento do músculo cardíaco, ginecomastia (crescimento de mamas nos homens), esterilidade e hipertensão arterial.

Os diuréticos são drogas que aumentam o fluxo urinário em função da maior fração de água eliminada e, em vista disso, funcionam como agentes que mascaram o efeito das drogas. São utilizados para provocar perda de peso e mascaramento de doping. Seus efeitos secundários são desidratação, cãibra muscular, diminuição do volume sanguíneo, doenças renais, alterações do ritmo cardíaco e perda de sais minerais.

Os hormônios peptídicos, segundo Weineck (2005) e Ghiselli e Jardim (2007), correspondem a um grupo de substâncias químicas produzidas e secretadas pelas glândulas endócrinas e que são lançadas em pequenas quantidades na circulação sanguínea, ou derivadas de um processo industrial de síntese, transformação ou modificação. Circulam pelo sangue controlando várias funções no organismo, tais como: atividades de órgãos completos; níveis de sais, açúcares e líquidos no sangue; uso e armazenamento de energia; crescimento e desenvolvimento de um determinado organismo, sua reprodução e suas características sexuais. São utilizados para proporcionar aumento do volume e potência dos músculos, recuperação tecidual e aumento dos glóbulos vermelhos no sangue. Seus efeitos secundários são ginecomastia, acromegalia (crescimento desmedido das mãos, pés e rosto), compressão de nervos periféricos e hipertrofia cardíaca.

O Quadro 1 sintetiza a natureza destas substâncias, assinalando seus efeitos sobre a performance atlética/esportiva, bem como aqueles deletérios à saúde. 


\begin{tabular}{|c|c|c|}
\hline Substância & Efeitos benéficos ao rendimento físico & Efeitos deletérios à saúde \\
\hline Estimulantes & $\begin{array}{l}\text { Aumento da excitação; } \\
\text { Aumento da tolerância à dor. }\end{array}$ & $\begin{array}{l}\text { Redução do apetite; } \\
\text { Hipertensão arterial; } \\
\text { Palpitações; } \\
\text { Arritmia cardiaca; } \\
\text { Alucinação; } \\
\text { Diminuição da sensação de fadiga. }\end{array}$ \\
\hline Anabólicos & $\begin{array}{l}\text { Aumento do metabolismo basal; } \\
\text { Aumento do número de hemácias; } \\
\text { Aumento da capacidade respiratória; } \\
\text { Redução da taxa de gordura corporal; } \\
\text { Ganho de força e potência; } \\
\text { Maior tolerância ao exercício físico. }\end{array}$ & $\begin{array}{l}\text { Aumento da agressividade; } \\
\text { Puberdade precoce; } \\
\text { Atrofia testicular e infertilidade; } \\
\text { Ginecomastia; } \\
\text { Efeitos adversos sobre sistema } \\
\text { cardiovascular, } \\
\text { Lesões hepáticas (inflamação e tumores). }\end{array}$ \\
\hline Diuréticos & $\begin{array}{l}\text { Perda de peso; } \\
\text { Mascaramento do doping. }\end{array}$ & $\begin{array}{l}\text { Desidratação; } \\
\text { Cãibra muscular; } \\
\text { Diminuição do volume sanguíneo; } \\
\text { Doenças renais; } \\
\text { Alterações do ritmo cardíaco; } \\
\text { Perda de sais minerais. }\end{array}$ \\
\hline $\begin{array}{l}\text { Hormônios } \\
\text { peptídicos }\end{array}$ & $\begin{array}{l}\text { Aumento de volume e potencia muscular; } \\
\text { Recuperação tecidual; } \\
\text { Aumento dos glóbulos vermelhos no sangue. }\end{array}$ & $\begin{array}{l}\text { Ginecomastia; } \\
\text { Acromegalia; } \\
\text { Compressão de nervos periféricos; } \\
\text { Hipertensão cardíaca. }\end{array}$ \\
\hline
\end{tabular}

Quadro 1: Classificação de substâncias proibidas e efeitos orgânicos observados

O aumento do uso de substâncias ou métodos proibidos destinados a melhorar artificialmente o desempenho esportivo vem se tornando cada vez mais frequente no mundo. Diante deste panorama, a Agência Mundial Antidoping vem estimulando ações intensas das autoridades nacionais e internacionais visando evitar a obtenção de vantagem desleal de um competidor sobre os demais, além de preservar os aspectos éticos e morais do esporte e, sobretudo, a saúde dos atletas (DE ROSE et. al., 2004).

De acordo com esta agência, desde o primeiro dia de janeiro de 2008, foi incluído em seu regulamento o conceito de resultado atípico (RAT) (Atypical Findings - AF). Este tipo de resultado ocorre quando uma amostra que apresenta uma substância ilícita necessita de uma investigação mais aprofundada para definir se foi produzida de forma endógena ou se realmente é um achado analítico adverso (World Antidoping Agency, 2009a). Vale ressaltar que o Comitê Olímpico Brasileiro (COB) publica anualmente, desde 2001, um manual onde consta a denominação das substâncias e métodos proibidos pela World Antidoping Agency (WADA) no esporte e, também, uma listagem atualizada com o nome comercial dos medicamentos que são utilizados em diferentes situações clínicas. 
O controle antidoping em competição e fora de competição visa à identificação de substâncias diferentes. Enquanto o exame em competição inclui todas as classes de substâncias e de métodos proibidos, o exame fora de competição é mais específico, incluindo os agentes anabolizantes, os hormônios peptídicos, alguns beta-2 agonistas, os agentes com atividade antiestrogênica, os diuréticos e outros mascarantes. Estimulantes, narcóticos analgésicos e drogas sociais não são analisados nos exames fora de competição.

A confirmação de compostos químicos naturais em dopagem de atletas é, atualmente, um dos maiores problemas para o controle. Por isso é necessário encontrar critérios para discriminar o uso externo da produção natural destes compostos. Para tanto, frequentemente utilizam-se parâmetros de referência. Marques; Pereira e Aquino Neto (2003) descreveram os parâmetros baseados na população europeia, segundo os quais, após a administração de uma substância ocorre aumento da sua concentração. Uma suspeita de resultado positivo acontece quando a concentração estiver acima do limite superior da faixa de referência dos valores normais da população em estudo, ou seja, $10 \mathrm{ng} / \mathrm{ml}$, ou quando leva à excreção da própria substância e de seus metabólitos.

Atualmente, uma nova abordagem no controle dessas substâncias vem sendo empregada. $\mathrm{O}$ enfoque consiste em metodologias de triagem dos supostos resultados positivos que têm o objetivo de rastrear a maior gama possível de compostos dentro de uma classe específica de agentes considerados proibidos e posterior confirmação por cromatografia gasosa acoplada à espectrometria de massa por razão isotópica (CG-EMRI) (MARQUES, et. al., 2003). Desde 1983 foi estabelecida a razão

Testosterona/Epitestosterona urinária maior que seis $(\mathrm{T} / \mathrm{E}>6)$ para a constatação do uso de ésteres de testosterona por atletas e esportistas (VAN DE KERKHOF; DE BOER; THIJSSEN; MAES, 2000).

No futuro, algumas técnicas genéticas serão utilizadas para mudanças da constituição genética que poderão significar ganho de força explosiva, resistência de força, reconstrução de tecido lesionado, tratamento de lesões osteo-músculo-articulares que, atualmente, requerem cirurgias e longo período de reabilitação. Uma técnica utilizada é a transferência de células ou elementos genéticos capazes de estimular a produção de hormônios por meio de alteração dos genes, vírus ou proteínas modificadas para induzir o organismo a acelerar a 
produção interna de hormônios e, com isso, melhorar a performance. Outras maneiras que podem beneficiar geneticamente os atletas consistem em bloquear a atividade de genes prejudiciais, de ativar mecanismos de defesa imunológica ou, ainda, de produzir moléculas que adequem a estrutura do corpo do desportista às necessidades de seu esporte (NARDI; VENTURA, 2005).

Foi partindo da premissa e da perspectiva da terapia gênica que surgiu o termo Doping Genético, tendo sido debatido no encontro do Gene Therapy Working Group, promovido pelo COI. Na WADA, em 2004, o termo doping genético foi definido como "a utilização não terapêutica de genes, elementos genéticos e/ou células que têm a capacidade de melhorar o desempenho esportivo" (RAMIRES; RIBEIRO, 2005 , p. 10). Nesse encontro, foi possível observar que a terapia gênica, além da sua importância no diagnóstico e tratamento de doenças, tem grande potencial para uso indevido nos esportes e que sua detecção deve ser desenvolvida e aplicada (ARTIOLI; HIRATA; JUNIOR, 2007). Por outro lado, a principal preocupação com a terapia gênica é a utilização de vírus como vetor, por haver a possibilidade de o vetor viral sofrer mutações e replicação em seu código genético caso haja falha em sua preparação. Além disso, há também os riscos não relacionados ao vetor, mas aos impactos do gene inserido, tal como o aumento da viscosidade sanguínea pela grande quantidade de eritropoetina (EPO) (Ibidem). Segundo Artioli et. al. (2007), a terapia genética está apenas em estágio inicial de desenvolvimento e, atualmente, não há indícios de qualquer caso de atleta que tenha feito uso de manipulação gênica, da mesma forma que ainda não existem meios específicos de controle e detecção do doping genético.

Diante do esforço dedicado ao controle do uso de substâncias ilegais visando o aumento do desempenho esportivo, torna-se relevante o monitoramento dos casos de doping no esporte em todo o mundo. Assim, o objetivo deste trabalho é caracterizar o quantitativo de exames antidoping realizados no Brasil no ano de 2008, os resultados analíticos adversos e atípicos constatados, e os tipos de substâncias mais utilizadas na dopagem. 


\section{Materiais e Métodos}

Modelo de pesquisa

A pesquisa se caracteriza como descritiva, na medida em que busca conhecer as diversas situações e relações de determinados fenômenos ou população numa dada realidade, sem manipulá-los (VALENTIM, 2005). Caracteriza-se, ainda, como retrospectiva, pois recorre à revisão e análise de registros referentes a exames antidoping realizados no Brasil no ano de 2008, portanto, anterior a realização desta pesquisa.

Amostra

A amostra deste estudo consistiu de 4.621 exames, sendo $4.587 \mathrm{em}$ competição e 34 fora de competição, representando o total de exames realizados no ano de 2008 em nível nacional.

Procedimentos de obtenção de dados

Para a obtenção dos dados recorreu-se ao Laboratório de Controle de Dopagem da Universidade Federal do Rio de Janeiro (LABDOP), credenciado desde 2002 pelo Comitê Olímpico Internacional (COI) e acreditado pela World Anti-doping Agency, bem como ao Comitê Olímpico Brasileiro (COB) que dispõe de autonomia para convocar atletas a realizar testes de controle antidoping.

Em nenhum momento os pesquisadores tiveram acesso à identidade dos atletas. A pesquisa não incidiu em experimento com seres humanos. O procedimento adotado para a obtenção dos dados foi, no primeiro momento, esclarecer os objetivos da pesquisa e, no segundo, solicitar a autorização das entidades responsáveis para a liberação das informações sobre os resultados de exames realizados no ano de 2008, visando à divulgação científica. Sendo assim, a pesquisa não incide em questões antiéticas na medida em que preserva o anonimato dos atletas e não exacerba distinções, diferenciações ou discriminações, não incidindo em quaisquer constrangimentos pessoais. Ainda assim, os procedimentos da pesquisa foram objeto de análise do Comitê de Ética na Pesquisa da Universidade Federal Rural do Rio de Janeiro, sendo aprovados mediante o protocolo número COMEP23083.012083/2011-73. 
Análise dos dados

Os dados obtidos foram catalogados e em seguida submetidos à análise estatística descritiva, utilizando-se frequência relativa e absoluta. Os dados foram processados e analisados através do aplicativo Microsoft Office Excel 2007 e os resultados apresentados em forma de tabelas e gráficos.

\section{Resultados e Discussão}

No ano de 2008, foram realizados 4.621 exames, sendo $4.587 \mathrm{em}$ competição $(99,26 \%)$ e 34 fora de competição $(0,74 \%)$ (Tabela 1$)$.

Tabela 1: Total de exames realizados no ano de 2008 e ocorrência de RAA e RAT

\begin{tabular}{l|c|c|c|c|c|c|c|c}
\hline \multirow{2}{*}{$\begin{array}{l}\text { Resultados } \\
\text { Exames }\end{array}$} & \multicolumn{2}{|c|}{ Negativo } & \multicolumn{2}{c|}{ RAA } & \multicolumn{2}{c}{ RAT } & \multicolumn{2}{c}{ Total } \\
\cline { 2 - 9 } & N & $\%$ & N & $\%$ & N & $\%$ & N & $\%$ \\
\hline Em competição & 4543 & 99,04 & 23 & 0,50 & 21 & 0,46 & 4587 & 100 \\
\hline Fora de competição & 26 & 76,47 & 2 & 5,88 & 6 & 17,65 & 34 & 100 \\
\hline \multirow{2}{*}{ Total } & 4569 & 98,88 & 25 & 0,54 & 27 & 0,58 & 4621 & 100 \\
\hline
\end{tabular}

Fonte: LAB DOP - LADETEC / IQ- UFRJ, Brasil, Rio de Janeiro. RAA = Resultado Analítico Adverso; RAT= Resultado Atípico.

Considerando os exames em competição, verifica-se que 99,04\% resultaram negativo, $0,50 \%$ apresentaram resultado analítico adverso (RAA) e 0,46\% resultado atípico (RAT), constatando-se o equilíbrio na magnitude destes últimos. Relativamente aos exames fora de competição, 76,47\% resultaram negativo, enquanto 5,88\% apresentaram resultado analítico adverso (RAA) e 17,65\% resultado atípico (RAT). Comparativamente, os exames fora de competição apresentam menor proporção de negativo e maior frequência de casos positivos, principalmente em resultados analíticos atípicos. Se considerado o somatório das duas categorias de exames, verifica-se que 98,88\% resultaram negativo, voltando a se notar o equilíbrio entre RAA e RAT caracterizados por $0,54 \%$ e $0,58 \%$ do total de exames respectivamente.

Os exames realizados em competição abrangeram as modalidades de atletismo, basquete, tiro, vôlei, vôlei de praia, futebol, triatlo, judô, levantamento de peso, esgrima, natação, automobilismo, surf, rugby e 
futsal. Observando a Tabela 2, verifica-se que dentre as modalidades relacionadas, o futebol totaliza 3.774 exames, representando $82,28 \%$ daqueles realizados em competição e $81,91 \%$ de todos os exames realizados naquele ano (em competição e fora de competição).

Tabela 2: Resultados de exames em competição realizados no ano de 2008

\begin{tabular}{|c|c|c|c|c|c|c|c|c|c|c|c|c|}
\hline \multirow[b]{2}{*}{ Modalidades } & \multicolumn{3}{|c|}{ Negativo } & \multicolumn{3}{|c|}{ RAA } & \multicolumn{3}{|c|}{ RAT } & \multicolumn{3}{|c|}{ Total } \\
\hline & $\mathbf{N}$ & $\begin{array}{c}\% \\
\text { Neg }\end{array}$ & $\begin{array}{c}\% \\
\text { Tot }\end{array}$ & $\mathbf{N}$ & $\begin{array}{c}\% \\
\text { RA } \\
\text { A }\end{array}$ & $\begin{array}{l}\% \\
\text { Tot }\end{array}$ & $\mathbf{N}$ & $\begin{array}{c}\% \\
\text { RAT }\end{array}$ & $\begin{array}{c}\% \\
\text { Tot }\end{array}$ & $\mathbf{N}$ & $\begin{array}{c}\% \\
\text { Mod }\end{array}$ & $\begin{array}{l}\% \\
\text { Tot }\end{array}$ \\
\hline Atletismo & 432 & 9,51 & 9,42 & 2 & 8,70 & 0,04 & 1 & 4,76 & 0,02 & 435 & 100 & 9,48 \\
\hline Basquete & 16 & 0,35 & 0,35 & 0 & 0,00 & 0,00 & 0 & 0,00 & 0,00 & 16 & 100 & 0,35 \\
\hline Tiro & 60 & 1,32 & 1,31 & 0 & 0,00 & 0,00 & 0 & 0,00 & 0,00 & 60 & 100 & 1,31 \\
\hline Vôlei & 103 & 2,27 & 2,25 & 3 & $\begin{array}{c}13,0 \\
4 \\
\end{array}$ & 0,07 & 0 & 0,00 & 0,00 & 106 & 100 & 2,31 \\
\hline Vôlei de praia & 9 & 0,20 & 0,20 & 0 & 0,00 & 0,00 & 0 & 0,00 & 0,00 & 9 & 100 & 0,20 \\
\hline Futebol & 3747 & 82,48 & 81,69 & 10 & $\begin{array}{c}43,4 \\
8\end{array}$ & 0,22 & 17 & 80,95 & 0,37 & $\begin{array}{c}377 \\
4\end{array}$ & 100 & 82,28 \\
\hline Triatlo & 6 & 0,13 & 0,13 & 0 & 0,00 & 0,00 & 0 & 0,00 & 0,00 & 6 & 100 & 0,13 \\
\hline Judô & 1 & 0,02 & 0,02 & 0 & 0,00 & 0,00 & 0 & 0,00 & 0,00 & 1 & 100 & 0,02 \\
\hline Lev. de Peso & 14 & 0,31 & 0,31 & 1 & 4,35 & 0,02 & 1 & 4,76 & 0,02 & 16 & 100 & 0,35 \\
\hline Esgrima & 2 & 0,04 & 0,04 & 0 & 0,00 & 0,00 & 0 & 0,00 & 0,00 & 2 & 100 & 0,04 \\
\hline Natação & 4 & 0,09 & 0,09 & 0 & 0,00 & 0,00 & 0 & 0,00 & 0,00 & 4 & 100 & 0,09 \\
\hline Automobilismo & 30 & 0,66 & 0,65 & 5 & $\begin{array}{c}21,7 \\
4\end{array}$ & 0,11 & 0 & 0,00 & 0,00 & 35 & 100 & 0,76 \\
\hline Surf & 2 & 0,04 & 0,04 & 0 & 0,00 & 0,00 & 0 & 0,00 & 0,00 & 2 & 100 & 0,04 \\
\hline Rugby & 2 & 0,04 & 0,04 & 0 & 0,00 & 0,00 & 0 & 0,00 & 0,00 & 2 & 100 & 0,04 \\
\hline Futsal & 115 & 2,53 & 2,51 & 2 & 8,70 & 0,04 & 2 & 9,52 & 0,04 & 119 & 100 & 2,59 \\
\hline Total & 4543 & 100 & 99,05 & 23 & 100 & 0,50 & 21 & 100 & 0,45 & $\begin{array}{c}458 \\
7\end{array}$ & 100 & 100 \\
\hline
\end{tabular}

Fonte: LAB DOP - LADETEC / IQ- UFRJ, Brasil, Rio de Janeiro. RAA = Resultado Analítico Adverso; RAT= Resultado Atípico.

Obs.: incluía um resultado presumível, ainda em análise.

Ainda em relação ao futebol, foi à modalidade esportiva que apresentou a maior proporção de positividade, representando $43,48 \%$ dos casos de resultado analítico adverso (RAA) e $80,95 \%$ dos casos de resultado atípico (RAT). Na sequência aparece o atletismo com 435 exames, representando $9,48 \%$ dos casos analisados, os quais apresentam índices de positividade de $8,70 \%$ do total de RAA e $4,76 \%$ do total de RAT identificados no ano de 2008. O futsal com 119 exames aparece como terceira modalidade em quantitativo de análises, as quais incidiram em $8,70 \%$ em relação ao total de RAA e 9,52\% em relação ao to- 
tal de RAT, seguido do vôlei, que dentre 106 análises apresentou $13,04 \%$ do total de RAA e nenhum caso de RAT em exames em competição. É de referir que as modalidades basquete, tiro, vôlei de praia, triatlo, judô, esgrima, natação, surf e rugby não apresentaram nenhum caso caracterizado em RAA e/ou RAT.

Verificou-se que existem mais casos de doping no futebol do que em outras modalidades, e nesta realizou-se o maior número de testes de controles de dopagem devido à frequência de partidas que acontecem no Brasil. Em estudo semelhante, De Rose et. al. (2004) verificou que no ano de 2003 foram realizados 3.797 exames, dentre os quais fica evidente a predominância de analises realizadas no âmbito do futebol em relação aos demais esportes. Segundo tais autores, o índice de positividade para o futebol foi de $0,27 \%$, valor cerca de três vezes e meio menor que o valor encontrado nesta pesquisa $(0,92 \%)$ considerando os resultados positivos em competição e fora de competição realizados nesta modalidade esportiva. Este valor também se mostra superior aos dados apresentados pela Fédération Internationale de Football Association (FIFA) os quais denunciam a incidência de casos positivos no futebol nos últimos 11 anos à proporção de $0,12 \%$, cerca de $0,42 \%$ em 2004 (com base no pressuposto de 20.750 amostras por ano) e 0,37\% em 2005 (DVORAK; GRAF-BAUMANN; D'HOOGLE; KIRKENDALL; TAENNLER; SAUGY, 2006).

O crescente uso de substâncias encontrados nos exames da modalidade futebol no Brasil pode estar relacionado, para além da pressão competitiva por resultados, pela busca de status socioeconômico, tendo em vista a origem carente da qual advém a maioria dos atletas de futebol. O baixo nível educacional desses atletas os torna vítimas neste contexto devido à ignorância sobre as consequências do uso de drogas utilizadas na dopagem.

A Figura 1 identifica os tipos de substâncias proibidas nos exames realizados em competição. Dos 4.587 exames realizados, cerca de 1\%, correspondente a 44 amostras, foram consideradas positivas. 


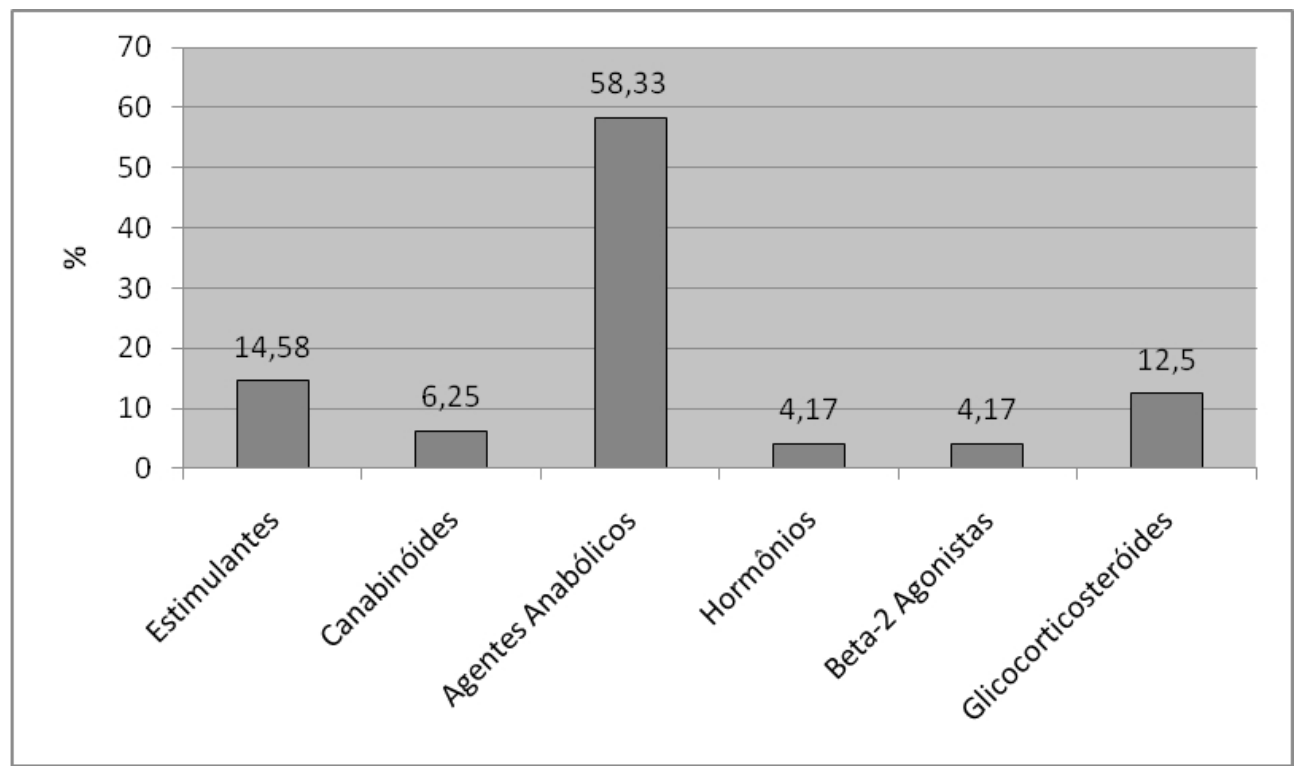

Figura 1: Proporção de substâncias proibidas identificadas no controle antidoping em competição no ano de 2008

Verifica-se a predominância dos agentes anabólicos $(58,33 \%)$, seguido de estimulantes $(14,58 \%)$ e glicocorticosteróides $(12,50 \%)$. As substâncias que aparecem com menor proporção são os canabinóides $(6,25 \%)$, hormônios $(4,17 \%)$ e os beta-2 agonistas $(4,17 \%)$. De acordo com os dados da Agência Mundial Antidoping, em relação aos resultados adversos apresentados por De Rose (2007), a proporção de anabólicos esteróides $(43,4 \%)$ e de estimulantes $(11,7 \%)$ ratificam os dados encontrados neste estudo. Entretanto, a proporção de $14,2 \%$ de beta-2 agonistas, citada pelo autor, supera significativamente os dados encontrados nesta pesquisa. De acordo com Silva et. al. (2002), há mais de 30 anos os esteróides anabolizantes penetraram nos esportes olímpicos. Esse dado é ressaltado, também, no estudo de De Rose et. al. (2004), no qual evidenciam que a maioria das substâncias encontradas em competição são os agentes anabólicos, seguido dos estimulantes, diuréticos, hormônios, canabinóides e narcóticos com valores menos expressivos em termos quantitativos.

Também foram objeto de análise desta pesquisa os exames realizados fora de competição, os quais abrangeram as modalidades de natação, atletismo, fisiculturismo, futebol e surf. $O$ atletismo foi a modalidade em que se verificou maior número de análises, representando $47,06 \%$ de todos os exames fora de competição e 9,76\% de todos os exames realizados naquele ano (em competição e fora de 
competição). Assim, como acontece nos exames em competição, também nos exames fora de competição verifica-se a prevalência de resultados analíticos adversos (RAA) e resultados atípicos (RAT) no futebol, representando a totalidade de análises positivas em relação aos demais esportes, na medida em que as modalidades natação, atletismo e fisiculturismo não apresentaram nenhum caso caracterizado como RAA e RAT (Tabela 3).

Tabela 3: Resultados de exames fora de competição realizados no ano de 2008

\begin{tabular}{|c|c|c|c|c|c|c|c|c|c|c|c|c|}
\hline Resultados & \multicolumn{3}{|c|}{ Negativo } & \multicolumn{3}{|c|}{ RAA } & \multicolumn{3}{|c|}{ RAT } & \multicolumn{3}{|c|}{ Total } \\
\hline Modalidades & $\mathbf{N}$ & $\begin{array}{c}\% \\
\text { Neg }\end{array}$ & $\begin{array}{c}\% \\
\text { Tot }\end{array}$ & $\mathbf{N}$ & $\begin{array}{c}\% \\
\text { RA } \\
\text { A }\end{array}$ & $\begin{array}{l}\% \\
\text { Tot }\end{array}$ & $\mathbf{N}$ & $\begin{array}{c}\% \\
\text { RAT }\end{array}$ & $\begin{array}{c}\% \\
\text { Tot }\end{array}$ & $\mathbf{N}$ & $\begin{array}{c}\% \\
\text { Mod }\end{array}$ & $\begin{array}{c}\% \\
\text { Tot }\end{array}$ \\
\hline Natação & 4 & 15,38 & 11,76 & 0 & 0,00 & 0,00 & 0 & 0,00 & 0,00 & 4 & 100 & 11,76 \\
\hline Atletismo & 16 & 61,54 & 47,06 & 0 & 0,00 & 0,00 & 0 & 0,00 & 0,00 & 16 & 100 & 47,06 \\
\hline Fisiculturismo & 2 & 7,69 & 5,88 & 0 & 0,00 & 0,00 & 0 & 0,00 & 0,00 & 2 & 100 & 5,88 \\
\hline Futebol & 3 & 11,54 & 8,82 & 2 & $\begin{array}{c}100, \\
00\end{array}$ & 5,88 & 6 & $\begin{array}{c}100,0 \\
0 \\
\end{array}$ & 17,65 & 11 & 100 & 32,35 \\
\hline Surf & 1 & 3,85 & 2,94 & 0 & 0,00 & 0,00 & 0 & 0,00 & 0,00 & 1 & 100 & 2,94 \\
\hline Total & 26 & 100 & 76,47 & 2 & 100 & 5,88 & 6 & 100 & 17,65 & 34 & 100 & 100 \\
\hline
\end{tabular}

Fonte: LAB DOP - LADETEC / IQ- UFRJ, Brasil, Rio de Janeiro. RAA = Resultado Analítico Adverso; RAT= Resultado Atípico.

Obs.: incluía um resultado presumível, ainda em análise.

No futebol, o RAA alcançou a proporção de 5,88\%, enquanto o RAT foi quase três vezes superior, com $17,65 \%$. De Rose et. al. (2004) comenta que os testes de controle de dopagem para o XIV Jogos Pan-Americanos em Santo Domingo, República Dominicana, em 2003, explicam o quantitativo de exames fora de competição realizado pelo Comitê Olímpico Brasileiro (14,0\%), bem maior que o encontrado nesta pesquisa $(0,74 \%)$. De acordo com o autor, no controle fora de competição, verificou-se $1,1 \%$ de casos positivos, destacando-se as modalidades de fisiculturismo (33,33\%), equestres $(22,2 \%)$, boxe $(7,6 \%)$ e natação $(2,5 \%)$, valores considerados mais altos que a referência internacional. É interessante observar que, embora na modalidade futebol tenham-se realizado o maior número de exames durante o ano de 2003, não foi constatado nenhum resultado positivo fora de competição, ao contrário do resultado verificado neste estudo, em que se acusa $23,53 \%$ de casos positivos fora de competição. 
Os resultados encontrados nos exames podem estar relacionados à intenção de minimizar o tempo necessário ao atleta para a consecução de resultados. A mídia tem publicado casos de atletas flagrados no exame antidoping no Brasil. Percebe-se que as sanções aplicadas variam muito de esporte para esporte. Enquanto em alguns esportes o critério de punição segue as normas internacionais da WADA, em outros se segue o Código Brasileiro de Justiça Desportiva, o qual prevê penalidades mais brandas. Este procedimento merece críticas, na medida em que as punições mais severas coibiriam de forma mais eficaz o uso de substâncias como forma de burlar as regras do esporte.

Na Figura 2 apresentam-se os tipos de substâncias proibidas identificadas nos exames realizados fora de competição no ano de 2008. Dos 34 exames realizados, oito amostras foram consideradas positivas.

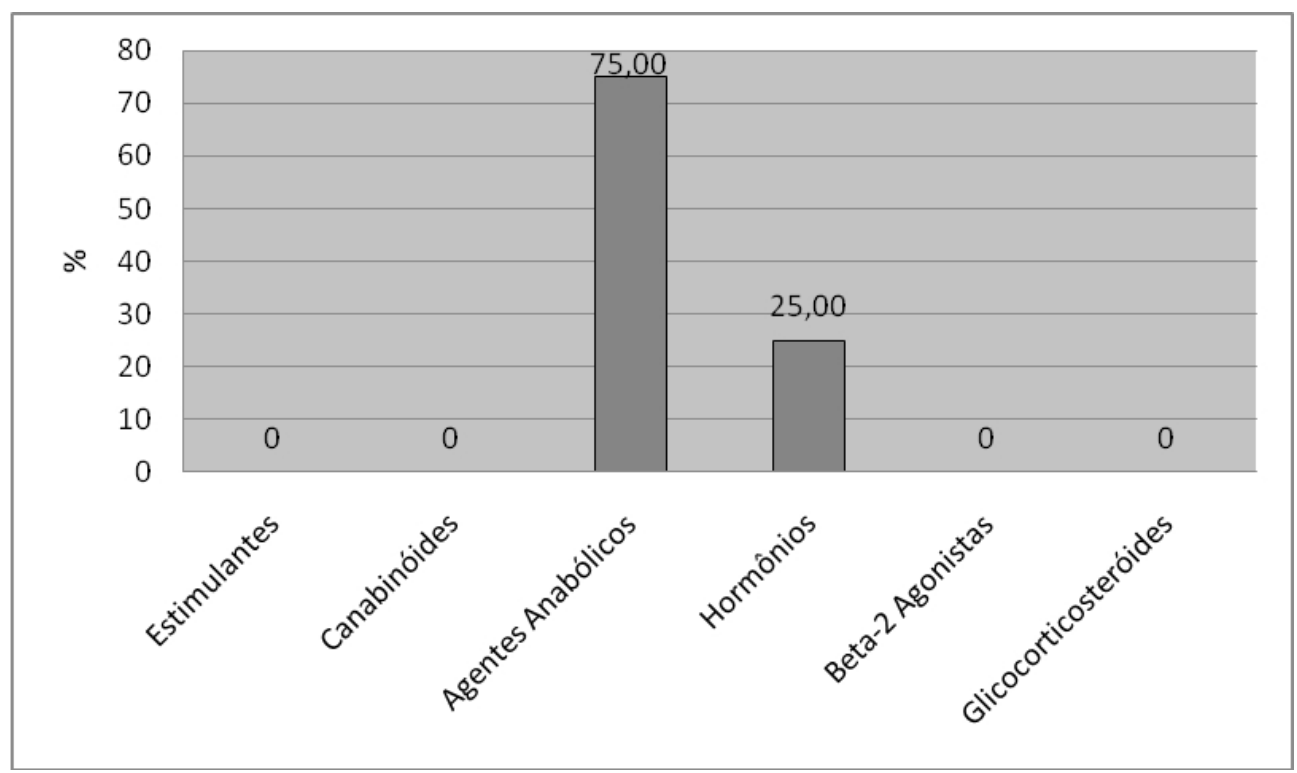

Figura 2: Proporção de substâncias proibidas identificadas no controle antidoping fora de competição no ano de 2008

A exemplo dos exames em competição verifica-se a predominância de agentes anabólicos $(75,00 \%)$, seguido de hormônios $(25,00 \%)$. As demais substâncias não foram objeto de nenhum caso positivo nas amostras.

De acordo com Ayotte; Goudreault e Charlebois (1996) e a World Anti-doping Agency (2008), as substâncias encontradas variam em função do esporte, do gênero e idade dos atletas. Conforme as estatísticas oficiais da WADA, em 2004, cerca de 0,7\% das 170.00 amostras apresentaram resultados analítico adverso para agentes anabólicos, 
dentre os quais $86 \%$ dos casos os esteróides utilizados foram a testosterona, o estanazolol e a metandienona. Nesta pesquisa, entre os esteróides utilizados, foi verificado o maior percentual de testosterona (75\%) em competição e fora de competição, salbutamol (10,71\%), norandrosterone $(7,14 \%)$, clostebol e a terbutalina $(3,75 \%)$.

O pragmatismo midiático e socioeconômico que eleva o atleta a um ente mítico, sublimando seu desempenho, performance e conquistas corroboram a criação de um estereótipo físico e estético, em geral, associados a um estado saudável. Porém, a evidência cada vez mais frequente de doping no meio esportivo contribui para deturpar tais conceitos na medida em que cada vez mais jovens e adolescentes, na ânsia por resultados imediatos, passam a considerá-la uma via para a consecução de resultados imediatos no que tange à estética ou ao rendimento esportivo.

O uso indiscriminado das drogas ilícitas não se restringe apenas aos atletas de elite ou competitivos (BAPTISTA; RODRIGUES; DAHER; DIOGUARDI; GHORAYEB, 2005). A utilização dessas drogas por adolescente nas academias chega a caracterizar um problema de saúde pública. Proliferam as academias irresponsáveis, a comercialização de drogas em farmácias alopatas ou de manipulação que utilizam sais legalmente importados, como oxandrolona, estanozolal e testosterona (LISE; SILVA; FERIGOLO; BARROS, 1999). Baptista et. al. (2005) ressaltam, ainda, que estas substâncias também são comercializadas via internet com requintes de sofisticação na compra e entrega personalizada, sem responsabilidade de quem as vende e, mais inaceitável, o incentivo à prescrição e às indicações ao seu acesso por profissionais ligados à área de saúde, os quais deveriam combater essa atitude com discussões temáticas sobre doping e seus riscos.

A cobertura espetaculosa dos casos de doping pela mídia sobrevaloriza a informação sobre os ganhos de performance e resultados positivos com o uso destas drogas, em detrimento de melhor esclarecer os seus efeitos colaterais, dessa forma, podendo estimular jovens atletas e praticantes de atividade física a sua utilização visando a busca de vitórias ou do "corpo perfeito" (MALULY, 2005). Não são raros os estudos que abordam a ocorrência de doping entre atletas novatos, adolescentes e em academias, mais especificamente entre praticantes de trabalho de força, comumente denominado musculação (MALULY, 2005; IRIART; ANDRADE, 2002; LOBO; NAPPO; SANCHEZ; CARLINI, 2003).

Pensar a Prática, Goiânia, v. 15, n. 3, p. 272-550, jul./set. 2012 
A confirmação do recurso ao doping por um atleta passa por diferentes procedimentos e instâncias de julgamento. A mídia deve adotar uma postura mais democrática e científica na divulgação de casos de doping, pois as informações sobre o uso dessas drogas podem auxiliar na diminuição do consumo de tais substâncias por indivíduos comuns. Por outro lado, a adoção de um protocolo de cobertura dos casos de doping evitaria condenar, à partida, os atletas indiciados de ingestão fraudulenta de substâncias proibidas. Os equívocos da mídia nas coberturas de casos de doping se mostram tão evidentes que Maluly (2006) apresenta um protocolo de procedimentos para a cobertura destes casos, visando qualificar o trabalho de jornalistas esportivos evitando, assim, macular precipitadamente a vida pessoal e a carreira de atletas inocentes.

\section{Conclusões}

O controle antidoping no Brasil tem sido realizado anualmente e os métodos de utilizados face aos avanços científicos, são cada vez mais eficazes na identificação do uso de substâncias dopantes. Esta pesquisa se reportou à totalidade dos exames antidoping realizados no ano de 2008. O maior número de análises em competição provém do futebol, enquanto o atletismo responde pela grande maioria dos exames realizados fora de competição.

Entre os exames que apresentam positividade em RAA e/ou RAT realizados em competição, aparecem com maior frequência o futebol, o automobilismo, o futsal, o atletismo, o vôlei e o levantamento de peso, nesta ordem. No que diz respeito aos exames fora de competição, apenas o futebol apresenta casos positivos em RAA e RAT.

Os esteróides anabolizantes, os estimulantes e os glicocorticosteróides representam $3 / 4$ das substâncias encontradas nos exames positivos em competição, ratificando a proporção encontrada em outros estudos, principalmente no que diz respeito aos anabolizantes e estimulantes. Nos exames fora de competição os anabolizantes e hormônios apareceram nos resultados adversos encontrados exclusivamente no futebol. Destaca-se que os índices encontrados no futebol são superiores aos dados divulgados pela FIFA, quer em 2004, quer na última década. Certamente o nível sócioeconômico de nossos atletas nesta modalidade e a premente necessidade de promoção social influenciam estes resultados. 
A literatura aponta a manipulação genética como a próxima geração de doping a ser utilizada pelos atletas. Apesar dos avanços tecnológicos que permitem o aperfeiçoamento na identificação de substâncias adversas no organismo, ainda não é possível diagnosticar com apuramento esta forma de dopagem. A despeito das evidências científicas demonstrarem sua valia para o diagnóstico e tratamento de lesões, preocupa a sua utilização desmedida, principalmente em se tratando do recurso ao vírus como vetor, pois incorre em risco para os atletas. Além disso, continua a constituir um mecanismo questionável sob o ponto de vista ético e moral no âmbito do cenário esportivo.

O esporte passa por um processo similar ao da globalização do capital. A industrialização e a modernização são decisivas para a difusão cultural. O que se observa no esporte é a constituição de uma elite de atletas profissionais que não tem apenas uma bandeira nacional, mas sim um conjunto de marcas multinacionais a defender (PRONI; LUCENA, 2002). Neste contexto, a exigência da autosuperação pode induzir o atleta ao desejo de supremacia, para isso, se valendo da dopagem. Em vista da pressão por resultados e consequente remuneração, o atleta se torna refém de um sistema no qual, pensa, é excluído quem não ganha. Ignora que se no sentido restrito o esporte produz muito mais perdedores, no sentido lato, quem pratica o esporte lealmente é sempre vencedor.

Diante da crescente mercantilização do esporte, o doping afeta os atletas de alta performance, e por extensão, muitos praticantes comuns de atividade física. $\mathrm{O}$ doping atinge indistintamente atletas oriundos de todas as classes sociais, mas certamente, aqueles provenientes de classes menos favorecidas tornam-se as maiores vítimas desta prática por desconhecerem seus efeitos nefastos. Estes atletas buscam no esporte a oportunidade para ultrapassar as fronteiras da marginalização e discriminação social e, por ignorância, vêem nas drogas a oportunidade para acelerar o desenvolvimento atlético que lhes possibilitaria o alcance de marcas esportivas relevantes e, consequentemente, o reconhecimento e promoção sociais.

Questões éticas e estéticas merecem destaque na abordagem do doping tanto no âmbito desportivo, quanto no social. Quanto a ética, questiona-se a legalidade e propriedade do uso de substâncias ilícitas para potencializar a performance. Embora algumas discussões conduzam à possibilidade de liberação do uso de drogas sob o argumento de que teoricamente preservaria a igualdade de condições entre os atletas 
de elite (RAMADAS, 2001), os comprovados prejuízos à saúde fazem prevalecer o senso moral, o qual nos leva a rechaçar tal possibilidade. Por outro lado, tendo em vista que o controle anti-doping segue sempre passos atrás dos processos de dopagem, bem como as punições, por mais rígidas e severas, não parecem intimidar práticas desta natureza. As ações preventivas são vistas como alternativa no sentido de, desde a formação esportiva elementar, conjugar a formação física e atlética com o desenvolvimento de valores e ideais que permitam aos atletas autonomamente rejeitar a prática do doping.

A assunção do esporte livre do doping só se consolidará quando atletas, técnicos, autoridades e patrocinadores estiverem imbuídos do espírito esportivo, em que a honra, a concorrência leal, o respeito às regras, a igualdade, integridade e solidariedade sejam mais importantes que a vitória a qualquer custo. Assim será possível compreender o jogo limpo como catalisador dos valores éticos e morais do esporte, pois o importante na vida assim como na competição, não é apenas o triunfo absoluto, mas o empenho leal pela conquista.

\title{
Doping control in Brazil: monitoring the practice of doping
}

\begin{abstract}
The use of substances or forbidden methods to improve the performance has become more frequent in sports. This research objective is to characterize the results of drug test accomplished in Brazil in the year of 2008. The data were obtained in the Laboratory of Drug Test of the Federal University of Rio de Janeiro and Brazilian Olympic Committee, both recognized by the International Olympic Committee as well as by WADA. Four thousand six hundred twenty-one exams were accomplished in the year of 2008. The soccer was the modality that presented more cases of doping. The scientific progresses allow more sophisticated methods to control the use of drugs in sports.
\end{abstract}

Keywords: Doping. Sports. Fair Play. Drug Test. Athletic Performance.

\section{Control antidopaje en Brasil: seguimiento de la práctica de dopaje}

\section{Resumen}

El uso de sustancias o métodos prohibidos para mejorar el rendimiento ha sido más frecuente en el deporte. El objetivo de esta investigación es caracterizar los resultados de las pruebas de dopaje realizados en Brasil en 2008. La recogida de datos se llevó a cabo en el Laboratorio de Control de Dopaje de la Universidad Federal de Rio de Janeiro y el Comité Olímpico Brasileño, acreditados por el Comité Olímpico Internacional y la AMA. Se identificaron cuatro mil seiscientos veintiún exámenes en 2008. Fútbol fue el deporte con más casos de dopaje. Los avances 
científicos permiten métodos más sofisticados para controlar el dopaje en el deporte.

Palabras clave: Dopaje. Deporte. Juego Limpio. Prueba de la Droga. Rendimiento Deportivo.

\section{Referências}

AQUINO NETO, F. R. O papel do atleta na sociedade e o controle de dopagem no esporte. Revista Brasileira de Medicina do Esporte, Rio de Janeiro, v.7, n. 4, p. 138-148, ago. 2001.

ARGÜELLES, C. F; ZAMORA, E. H. Dopaje genético: transferência gênica y su posible detección molecular. Gaceta Médica de México, México, v. 143, n. 2, p. 169-172, mar./abr. 2007.

ARTIOLI, G. G; HIRATA, R. D. C; JUNIOR, A. H. L. Terapia gênica, doping genético e esporte: fundamentação e implicações para o futuro. Revista Brasileira de Medicina do Esporte, Rio de Janeiro, v. 13, n. 5, p. 349-354, out. 2007.

AYOTTE, C; GOUDREAULT, D; CHARLEBOIS, A. Testing for natural and synthetic anabolic agents in human urine. Journal of Chomatography B, Amsterdam, v. 687, p. 3-25, 1996.

BAPTISTA, C. A; RODRIGUES, E. R; DAHER, S; DIOGUARDI, G; GHORAYEB, N. Drogras lícitas e ilícitas nas academias e no esporte. Rev. Soc. Cardiológica do Estado de São Paulo, São Paulo, n. 3, p. 231-241, mai./jun. 2005.

CASTRO, R. R. T; NÓBREGA, A. C. L ; DE ROSE, E. H. XXVIII Olimpíadas, Atenas. O cardiologista está preparado? Arquivo Brasileiro de Cardiologia, Rio de Janeiro, v. 83, n.1, p.1-3 , jul. 2004.

DE ROSE, E. H; AQUINO NETO, F. R; NICOLICH, R. S. Informações sobre o uso de medicamento no esporte. Rio de Janeiro: COB Cultural, 2009. p. 1-74.

DE ROSE, E. H. Doping: a química vai ao Pan. Revista da Federação Nacional dos Profissionais da Química, Brasilia, n. 7, p.14-16, jan./mar. 2007. 
DE ROSE, E. H; AQUINO NETO, F. R; MOREU, R. L. M; CASTRO, R. R. T. Controle antidoping no Brasil: resultado do ano de 2003 e atividade de prevenção. Revista Brasileira de Medicina do Esporte, Rio de Janeiro, v.10, n. 4, p.289-293, ago. 2004.

DVORAK, J; GRAF-BAUMANN, T; D'HOOGHE, M; KIRKENDALL, D; TAENNLER, H; SAUGY, M. FIFA's approach to doping in football. British Journal of Sports Medicine, London, v. 40, p.1-20, jul. 2006.

GHISELLI, G; JARDIM, W. F. Interferentes Endócrinos no Ambiente. Revista Química Nova, São Paulo, v. 30, p. 695-706, mai.jun. 2007.

IRIART, J. A. B. \& ANDRADE, T. M. (2002, Set./Out.). Musculação, uso de esteróides anabolizantes e percepção de risco entre jovens fisiculturistas de um bairro popular de Salvador, Bahia, Brasil. Cadernos de Saúde Pública, 18(5). Disponível em http://www.scielo.br/. Acesso em: 04 abr. 2005.

LISE, M. L. Z; SILVA, T. S. G; FERIGOLO, M; BARROS, H. M. T. $\mathrm{O}$ abuso de esteróides anabólico-androgênicos em atletismo. Revista da Associação Medica Brasileira, São Paulo, v. 45, n. 4, p. 364-370, dez. 1999.

LOBO, A. P. T.; NAPPO, S. A.; SANCHEZ, Z. V. D.; CARLINI, E. A. $\mathrm{O}$ uso indevido de anabolizantes na cidade de São Paulo: um estudo qualitativo. J. Bras. Psiquiatr., Rio de Janeiro, v. 1, p. 25-34, 2003.

MALULY, L. V. B. Divulgação científica no esporte: um debate sobre doping e imprensa no Brasil. In: Congresso Brasileiro de Ciências da Comunicação, 26., 2005, Rio de Janeiro. Anais... São Paulo: Intercom, 2005. CD-ROM. Disponível em <http://hdl.handle.net/1904/18322>. Acesso em: 5 mar. 2012.

MALULY, L. V. B. . O doping e a cobertura jornalística no Brasil. Caligrama, São Paulo, v. 1, p. 1-12, 2006.

MARQUES, M. A. S; PEREIRA, H. M. G; AQUINO NETO, F. R. Controle de dopagem de anabolizante: o perfil esteroidal e suas regulações. Revista Brasileira de Medicina do Esporte, Rio de Janeiro, v. 9, n. 1, p.15-24, fev. 2003. 
NARDI, N. B; VENTURA, A. M. Terapia Gênica. In: MIR, L. Genômica. Rio de Janeiro: Atheneu, 2005. p. 625-664.

PRONI, M. W; LUCENA, R. F. Esporte: história e sociedade. São Paulo: Autores Associados, 2002. p. 10.

RAMADAS, S. C. Aspectos psicológicos do doping no desporto: atitudes dos jovens entre 16 e os 18 anos. 280 f. Dissertação (Mestrado em Psicologia do Desporto) - Curso de Mestrado em Psicologia do Deporto, Faculdade de Motricidade Humana, Lisboa, 2001.

RAMIRES, A; RIBEIRO, A. Doping genético e esporte. Revista Metropolitana de Ciências do Movimento Humano, São Paulo, v. 5, n. 2, p. 9-20, jun. 2005.

RIVIER, L. Is there a place for hair analysis in doping controls? Forensic Science International, Lausanne, v. 107, p. 309-323, jan. 2000 .

ROBERGS, R. A; SCOTT, O. R. Princípios Fundamentais de Fisiologia do Exercício: para Aptidão, Desempenho e Saúde. São Paulo: Phorte Editora, 2002. p. 250-264.

SILVA, P. R. P; DANIELSKI, R; CZEPIELEWSKI. M. A. Esteróides anabolizantes no esporte. Revista Brasileira de Medicina do Esporte, Rio de Janeiro, v. 8, n. 6, p. 235-243, dez. 2002.

VALENTIM, M. L. P. (Org.). Métodos qualitativos de pesquisa em Ciências da Informação. São Paulo: Polis, 2005.

VAN DE KERKHOF, D. H; DE BOER, D; THIJSSEN, J. H. H; MAES, R. A. A. Evaluation of testosterone/epitestosterone ratio influential factors as determined in doping analysis. Journal of Analytical Toxixology, Danvers, v. 24, n. 2, p. 102-115, mar. 2000.

VIEIRA, T. P. F. Doping no desporto. Porto: Universidade do Porto, 2006. 16 p. Dissertação (Mestrado) - Programa de Mestrado em atividade física e saúde, Universidade do Porto, Porto, 2006.

WEINECK, J. Biologia do esporte. São Paulo: Manole, ed. 7, 2005. p. 758 . 
WORLD ANTI-DOPING AGENCY. Adverse analytical findings reported by accredited laboratories, 2004. Montreal: WADA, 2008. Disponível em: <http://www.wada-ama.org/en/Science-Medicine/Anti-Doping-Laboratories/Laboratory-Statistics/>. Acesso em: 05 mar. 2008

WORLD ANTI-DOPING AGENCY. Code (Version 9). Montreal: WADA, 2009, p. 135. Disponível em: <http://www.wada-ama.org>. Acesso em: 19 jul. 2009 (a).

\section{Agradecimentos}

Ao Laboratório de Controle de Dopagem da Universidade Federal do Rio de Janeiro (LAB DOP) pela importante contribuição científica e incentivo na realização deste trabalho.

Ao Comitê Olímpico Brasileiro pelo apoio e contribuição.

A professora Giannina Laucas de Campos, pelo incentivo, amizade e oportunidade de aprendizado.

Recebido em: 19/12/2010

Revisado em: 07/05/2011

Aprovado em: 23/10/2011

Endereço para correspondência

henriquejoe@hotmail.com

José Henrique dos Santos

Universidade Federal Rural do Rio de Janeiro

Instituto de Educação, Departamento de Educação Física e Desportos.

Antiga Rodovia RJ/SP - Km $47, \mathrm{~s} / \mathrm{n}^{\circ}$

Campus Universitário

23890-000 - Seropedica, RJ - Brasil 